\title{
Assessment of Local Discomfort in Common Pencils and Ergonomic Designed Pencil With Local Discomfort Scale in Elementary School Students
}

\section{Rashid Heidari Moghadam ${ }^{1}$, Mohammad Babamiri ${ }^{2}$, Majid Motamedzadeh ${ }^{1}$, Nasrin Nouri ${ }^{3 *}$}

1. Department of Ergonomics, School of Public Health, Hamadan University of Medical Sciences, Hamedan, Iran

2. Research Center for Health Sciences, Department of Ergonomics, School of Public Health, Hamadan University of Medical Sciences, Hamadan, Iran

3. MSc in Ergonomics, Department Ergonomics, School of Health, Hamadan University of Medical Sciences, Hamedan, Iran

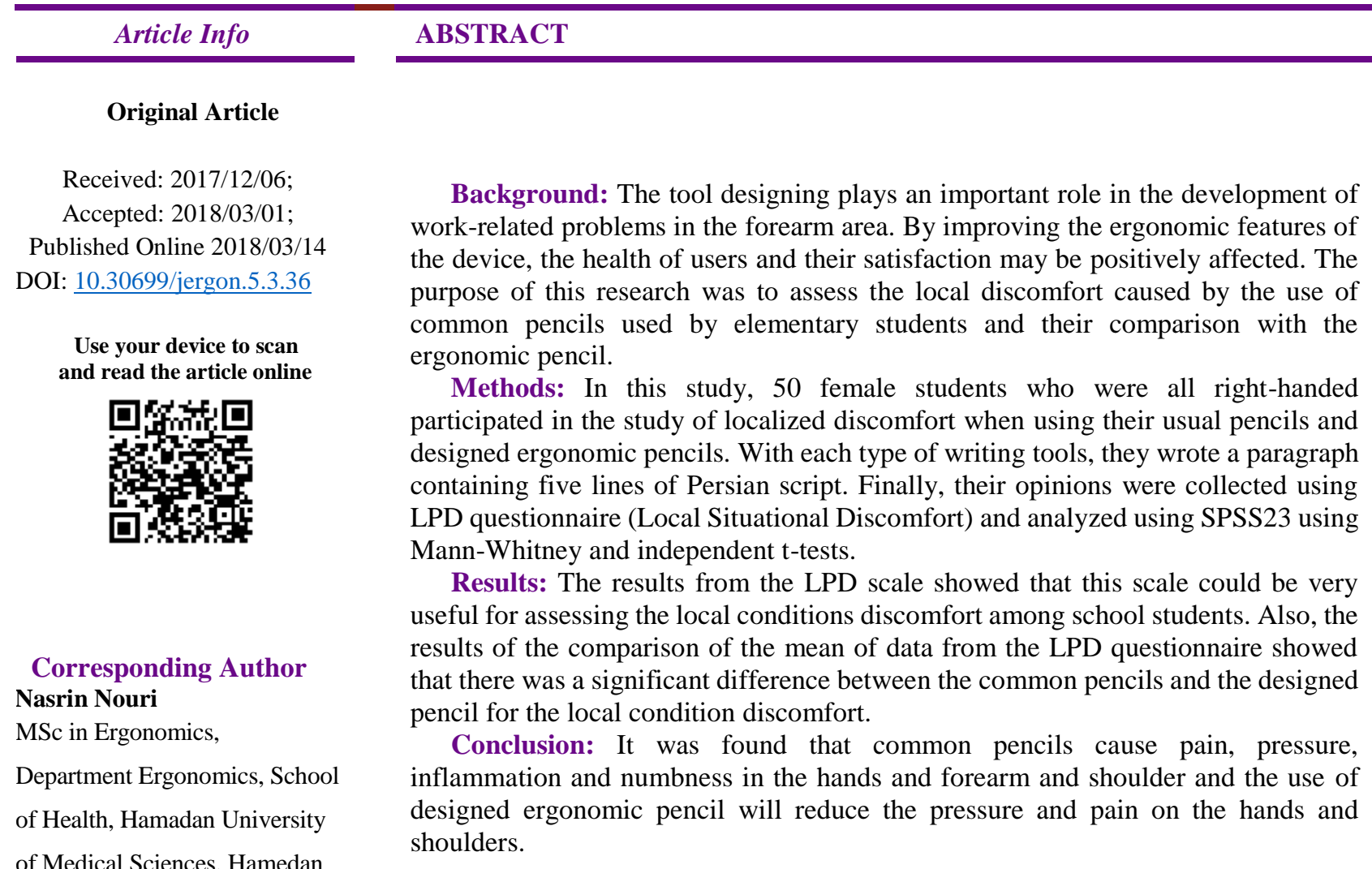

Keywords: Ergonomics, Writing tools, Pencil Designing, Students

Email:

nasrin.nouri1369@yahoo.com

Copyright $\odot$ 2018, Journal of Ergonomics. This is an open-access article distributed under the terms of the Creative Commons Attribution-noncommercial 4.0 International License which permits copy and redistribute the material just in noncommercial usages, provided the original work is properly cited.

\section{How to Cite This Article:}

Haidari Moghadam R, Babamiri M, Motamedzade M, Nouri N. Assessment of local discomfort in common pencils and ergonomic pencil designed with local discomfort scale in elementary school students. J Ergon. 2018; 5 (3) :36-40 


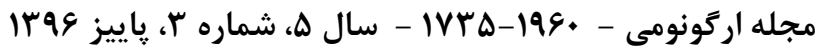

\section{مقاللَ يزوهشى}

ارزيابى ناراحتى موضعى در مدادهاى رايج و مداد ارَّونوميك طراحى شده با مقياس

ناراحتى وضعيتى موضعى در دانش آموزان مقطع ابتدايى

رشيد حيدرى مقدم'، محمد باباميرى ؟، مجيد معتمدزادها؛ نسرين نورى

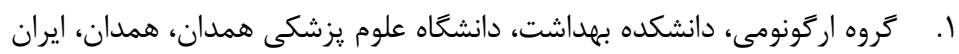

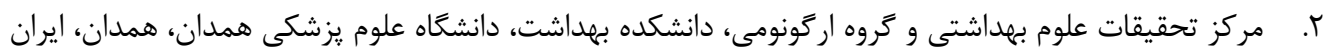

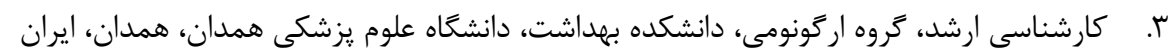

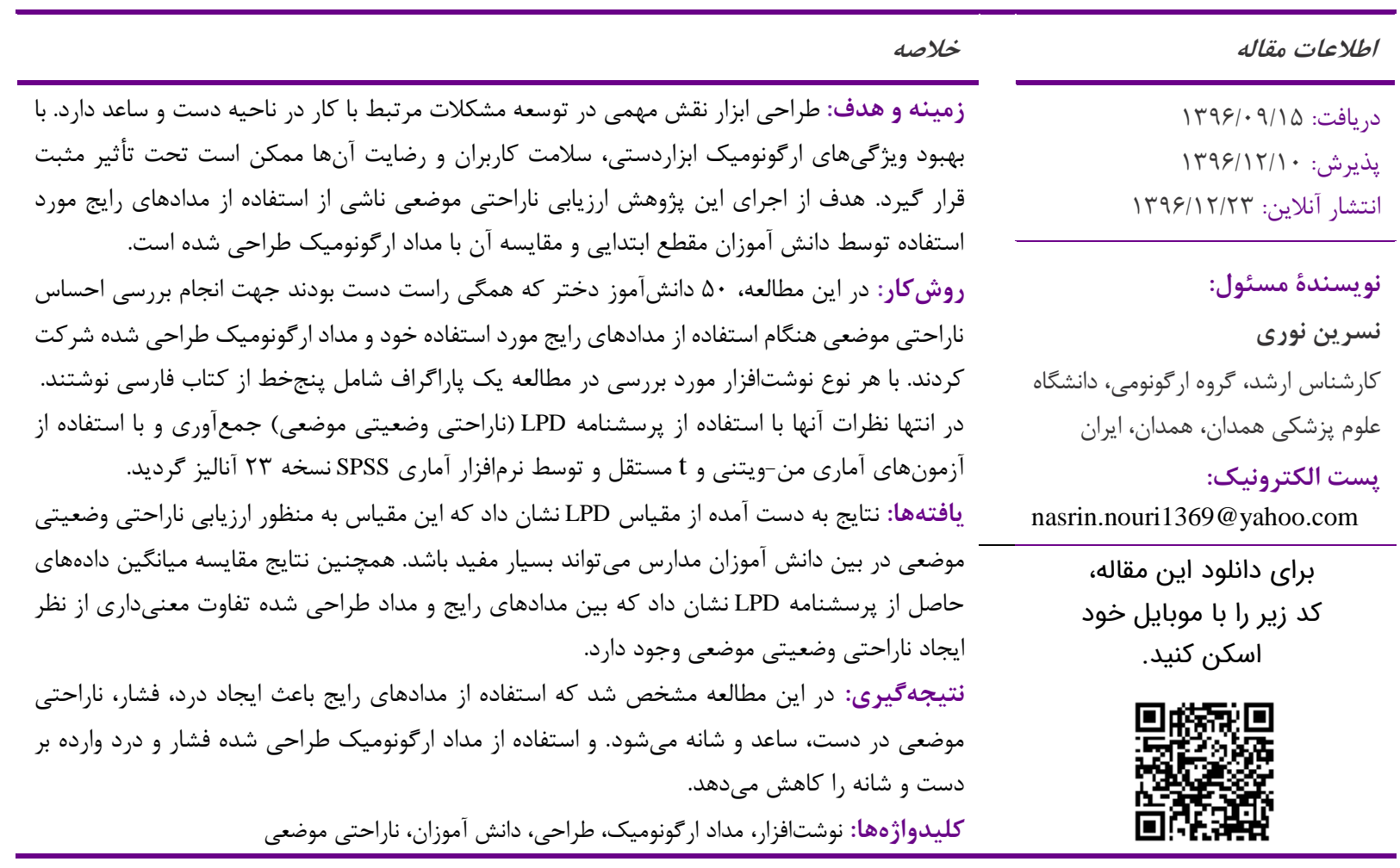

مقدمه

مهندسين بايد براى اطمينان از راحتى، ايمنى، كارايى و

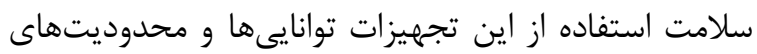
فيزيك و بدنى انسان را در طراحى و ساخت وسايل در نظر بخيرند [r]. در اين راستا، ارگونومى بهعنوان رهيافتى كار آمد،

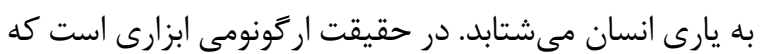
به كمك آن، انسان قادر است محيط زندگى انسى، كار و نيز وسايل و تجهيزات مورد استفاده را مطابق با توانمندىها و ويزگى هاى

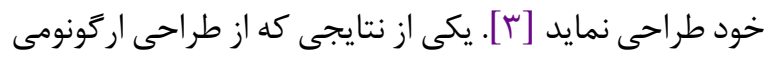
به دست مى آيد راحتى يا كاهش ناراحتى است. در واقع رابطه

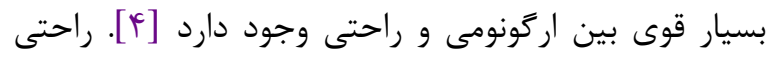

انسانها در زندگى روزمره خود با وسايل، تجهيزات و محيطهاى گوناگونى مواجه مىشوند. عدم تطابق و تناسب ميان

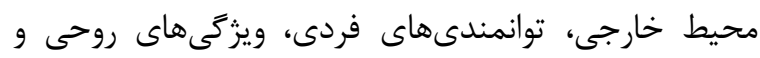
جسمى، موجب بروز خسارات فراوانى در جنبههاى گوناگون

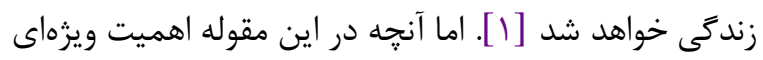
دارد، تفاوت افراد در ابعاد و اندازههاى بدنى، علائق و اولويتها و نيز محدوديتهاى جسمى و ذهنى است، كه بايستى در طراحى محيط زندگى، وسايل، تجهيزات و محيطهاى كار مورد

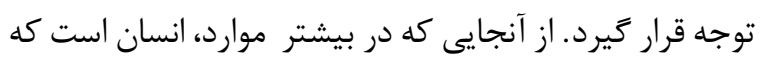

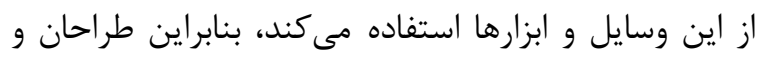




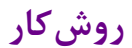

در اين مطالعه بلمنظور ارزيابى مدادهاى رايج و نيز مداد طراحى شده، دانش آموزان دبستان ابتدايى دخترانه شهيد

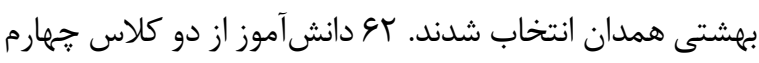

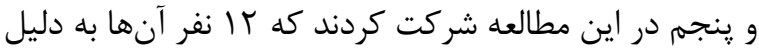
عدم دسترسى از مطالعه كنار كذاشته شد و آناليز روى •ـ نه نفر

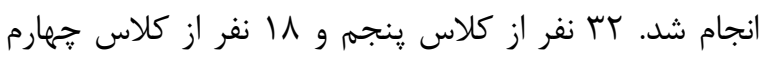
بودند. بر اساس نمونههاى مشابهى كه در مطالعات ديكر طراحى شده است، مدادى با ويزَىىهاى اركَونوميك با استفاده از داز

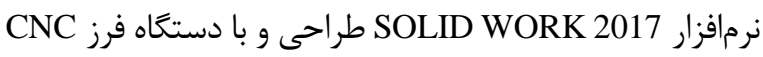

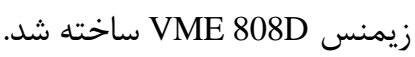
قطر بدنه مداد V/9 ميلىمتر و زاويه سر دو محوره مداد باد درجه در نظر گرفته شد [9]. در تحقيق حاضر، اطلاعات كسب شده از كلاسهاى مور مورد

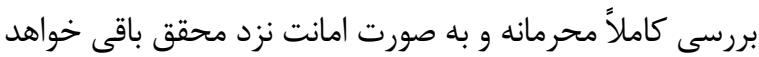
ماند. همجنين نتايج حاصل از بررسى هابـا با اطلاع دبستان شهيد بهشتى همدان انتشار خواهد يافت. متنى كه براى نوشتن كودكان در نظر كرفتهشده بود، از كتاب فارسى الهام كرفته و با سطح توان تحصيلى كودكان جهارم

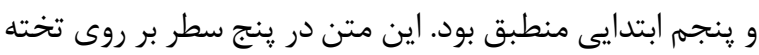

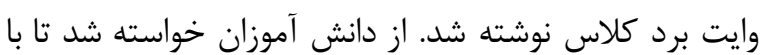

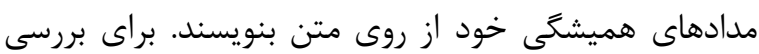

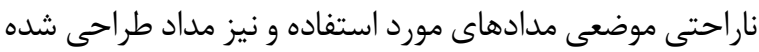
از يرسشنامه ناراحتى وضعيتى موضعى (LPD) استفاده كرديم.

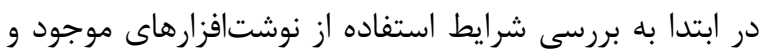

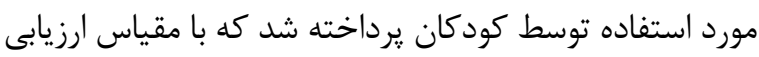

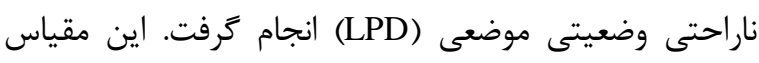

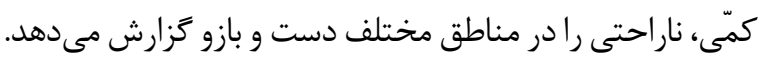

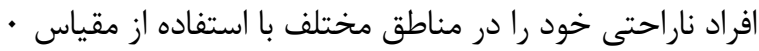

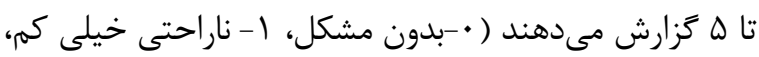

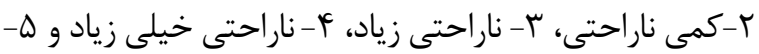

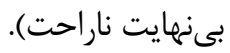

در نهايت دادهها با استفاده از نرمافزار آمارى SPSS نسخه

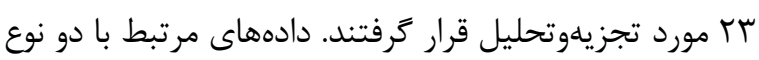

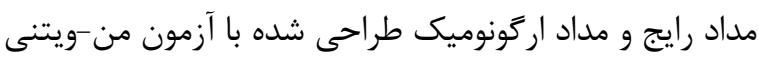

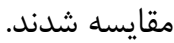
روايى و پايايى مقياس وضعيتى ناراحتى موضعى توسط

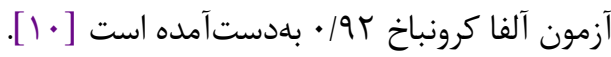

نقشى مهم در استفاده از ابزارهاى دستى ايفا مى كند. راحتى

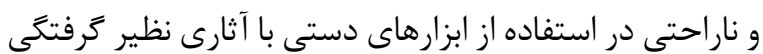

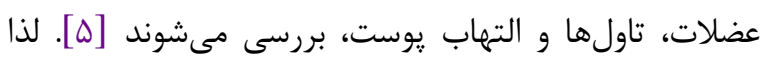

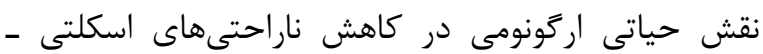

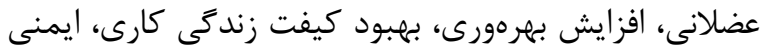

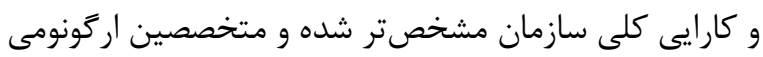
نيز با بهينه كردن تناسب بين انسان، ماشين و محيط، كارايى ماريى

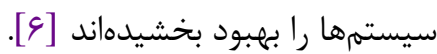

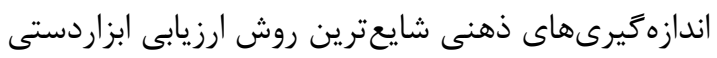

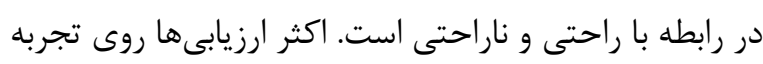

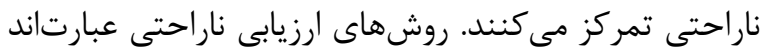

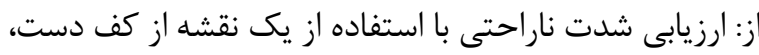

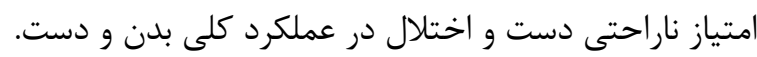
راحتى يك مفهوم يِيجيده است كه تركيبى از احساسات، ادراى، خلقوخوى و وضعيت را شامل مىشود. علاوه بر اين،

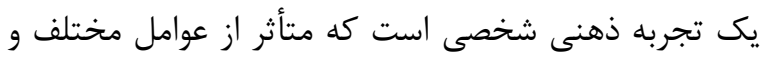

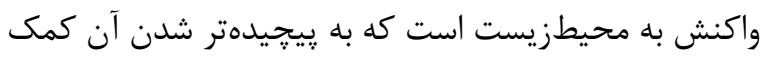
مى كند. ازاينرو، راحتى ممكن است تحت تأثير تعامل بين كاربر، ابزاردست و كار در يكى محيط باشد. علاون ملاوه بر اين،

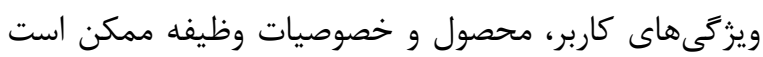

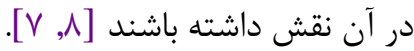

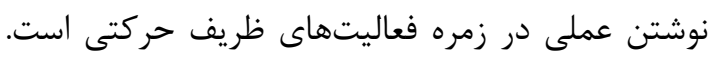

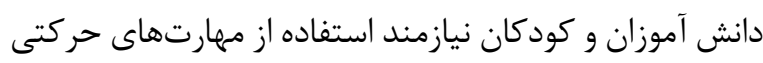
خوب در محيط كلاس درس هستند. در بيشتر زمان كلاس در مدرسه يا كلاسهاى آموزشى ديخر، كودكان در در حال

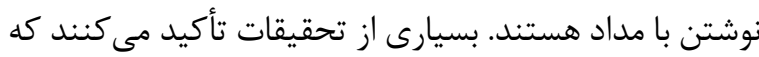

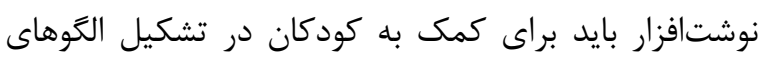
درست نوشتن بهخوبى طراحى كردند. اما آنها بلوضوح مشخص نكردند كه جه عواملى در طراحى شكل نوشتافزار

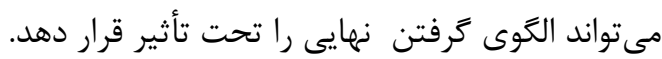
با توجه به مشكلاتى كه هنعام عمل نوشتن در كودكان وجود دارد لذا طراحى و ساخت مدادى كه بتواند الكَوى درست ندان

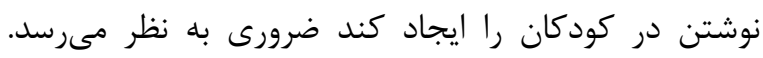

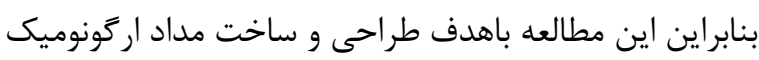
براى دانش آموزان طراحى شد. 
جدول شمارها ـ توزيع نمونه آمارى مورد مطالعه بر حسب سن افراد مورد مطالعه

\begin{tabular}{|c|c|c|c|c|}
\hline ت تعداد & انحراف معيار & ماكزيمم سن & مينيمم سن & ميانكين سن \\
\hline$\Delta$. & $\cdot / \uparrow \wedge \Delta$ & 11 & 1. & $1 . / 9 F$ \\
\hline
\end{tabular}
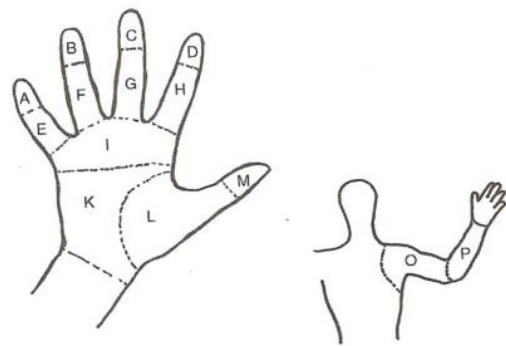

شكل شماره Y. طرح استفاده شده براى ارزيابى ناراحتى

وضعيتى موضعى (LPD)

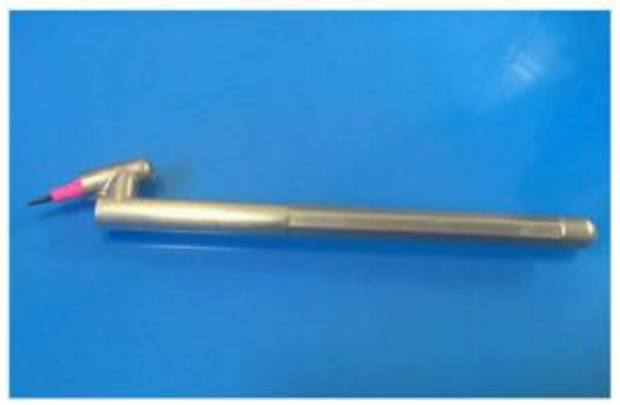

شكل شماره ا. مداد اركونوميك طراحى شده

موضعى (LPD) كمترى براى كاربران ايجاد مى كند. نرمال

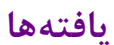

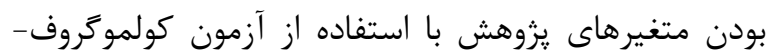
اسميرنف مورد بررسى قرار كرفت.كه براى دادهها فرض نرمال بردال

بودن برقرار نبود.(ه • • (p-value

بلهور كلى مقايسه استفاده از مدادهاى رايج و طراحى شده

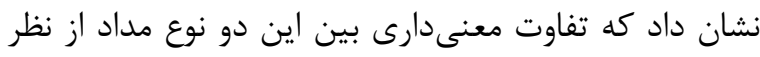

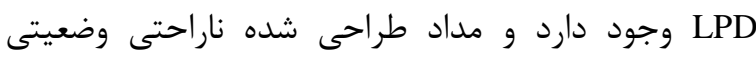

جدول شماره r. نتايج توصيفى مداد ارَّونوميك و مداد رايج

\begin{tabular}{|c|c|c|c|}
\hline انحراف معيار & ميانَين & تعداد & متغير \\
\hline $\mid r / 11 \Lambda$ & $8 / \pi$. & $\Delta$. & مداد اركونوميك \\
\hline $14 / 19$ & TF/VG & $\Delta$. & مداد رايج \\
\hline
\end{tabular}

جدول شماره r. جدول آزمون من -ويتنى براى متغير مدادهاى رايج و مداد اركونوميك

\section{p-value}

$\cdot 1 \cdot \cdot r$

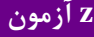

g/9Vr
اركونوميك ابزاردستى، سلامت كاربران و رضايت شغلى آنها

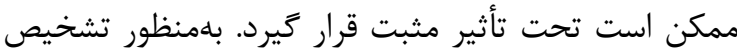

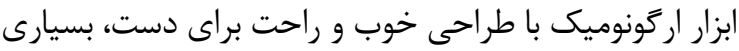

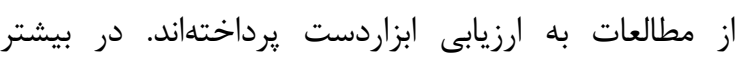
مطالعات، اندازهخيرىهاى عينى (براى اندازهخيرى بار فيزيكى)

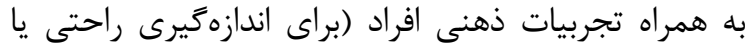
ناراحتى) انجام شده است [111]. اين مطالعات مقياس نار احتى إنى را در مناطق مختلف دست و بازو كزارش مى دهند. افراد

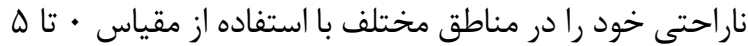

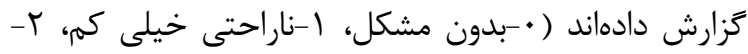

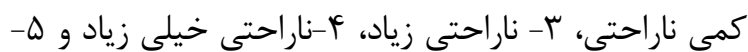
بنىنهايت ناراحت).

راحتى در استفاده از ابزار دستى و همجنين ميزان ييشبينى آنها توسط توصيفكرها و عوامل آنها (كروههاى توصيفكر) قابل بيشيينى هستند. ابزارهاى راحتى دستى لوسين
جهت آزمون اين فرضيه و بلمنظور تعيين معنىدارى تفاوت ميانكين بين دو مداد، از آزمون من-ويتنى استفاده

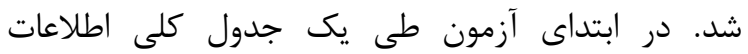
بهدستآمده از محاسبات توصيفشده براى إنى هريك از مدادها

$$
\text { برسى شد.(جدول شماره ؟) }
$$

جدول آزمون من-ويتنى مربوط بـ به متغير مقايسه دور

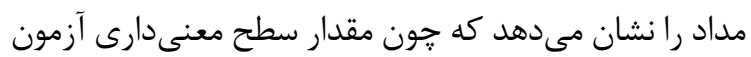
كمتر از هـ/• ( هـ/••value معنى دارى ميان دو مداد از لحاظ ايجاد ناراحتى وضعيتى

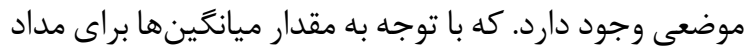

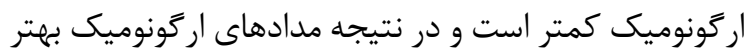

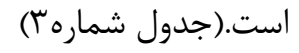

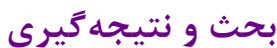

طراحى ابزار ممكن است نقش مهمى در توسعه مشكلات

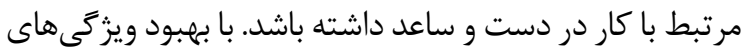




$$
\begin{aligned}
& \text { اين مطالعه تزارش نشده است. تحليل نتايج تفاوت } \\
& \text { معنى دارى بين مداد اركونوميك و مداد رايج كزارش مى كند. } \\
& \text { در مطالعه حاضر مشخص شد كه استفاده از مدادهاى }
\end{aligned}
$$

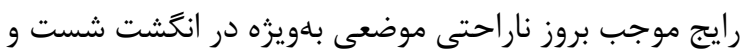

$$
\begin{aligned}
& \text { اشاره، ساعد و شانه مىشود. بر اساس نتايج مطالعه حاضر براض }
\end{aligned}
$$

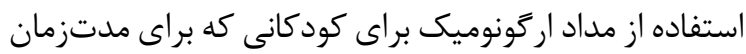

$$
\begin{aligned}
& \text { طولانى به وظيفه نوشتن مشغول هستند، باعث كاهش براي } \\
& \text { نار احتى هاى موضعى وارد بر نواحى مذكور مى فودن. }
\end{aligned}
$$

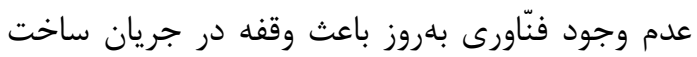

$$
\begin{aligned}
& \text { مداد شد بهكونهاى كه هيج كدام از شركتهاى توليدكنينده } \\
& \text { نوشتافزار قادر به ساخت مداد نبودند و از طرفى بودجه } \\
& \text { اختصاص داده شده براى ساخت مداد بسيار محدود بود. }
\end{aligned}
$$

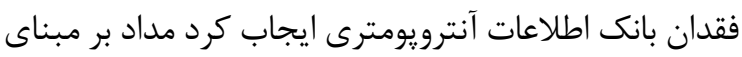

$$
\begin{aligned}
& \text { مطالعات بيشين و بر اساس دادهاى آنترويومترى كودكان } \\
& \text { كشورى غير از ايران توليد كردد كه بِيشنهاد مىشود مدادى } \\
& \text { بر اساس ويزگى هاى آنترويومترى كودكان اين مرز و و بوم } \\
& \text { طراحى و ساخته شود. } \\
& \text { تقدير و تشكر }
\end{aligned}
$$

نويسندكان مراتب تشكر و قدردانى خود را از مساعدت

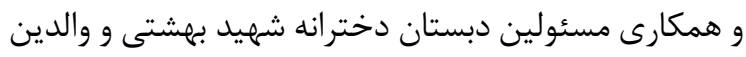

دانش آموزان شركت كننده در مطالعه اعلام مى دمارند.

$$
\text { تعارض منافع }
$$

بين نويسندًان هيجَّونه تعارضى در منافع وجود ندارد.

\section{References}

1. Vink P. Comfort and design: principles and good practice. CRC press; 2004. https://doi.org/10.1201 19781420038132.

2. Sharifi Z, Osqueizadeh R, Tabatabai Ghomshe SF. Ergonomic Redesign of Industrial Chair. J Ergon. 2015;3(1):1-9.

3. Cox T, Griffiths A. The nature and measurement of work-related stress: theory and practice. 2005. https://doi.org/10.1201/9781420055948.ch19.

4. Bridger R. Introduction to ergonomics. Crc Press; 2008.

5. Matern U, Koneczny S. Safety, hazards and ergonomics in the operating room. Surg Endosc. 2007 Nov;21(11):1965-9.

6. Buckle P. Ergonomics and musculoskeletal disorders: overview. Occup Med (Lond). 2005 May;55(3):164-7.
مىتوانند اثرات بدوى بدن كه باعث ناراحتى مىشوند را ييشبينى كنند، اما بهترين يِيشيينى كننده راحتى توصيف

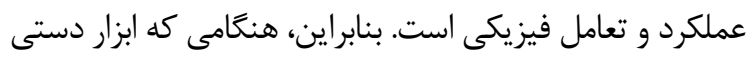

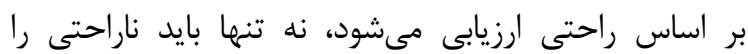
اندازهكيرى كند، بلكه بايد جنبههاى عملكرد و تعامل فيزيكى إنى را نيز مورد توجه قرار دهد. طراحان براى طراحى ابزارهاى دستى كه باعث راحتى زيادى مىشوند، بايد بر عملكرد و تعامل فيزيكى تمركز و از ناراحتى جلوكيرى كنند. شكل مداد (شبيه شكل حرف Z) بر ميزان تلاش در دست كرفتن، قابليت استفاده و اندازمخيرى امتيازات ناراحتى، كه مطابق با مطالعات قبلى است، قابل توجه است.

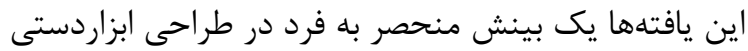

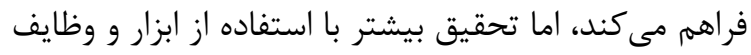
مختلف براى اعتبار يافتهها در ساير مقاطع تحصيلى، با نغاه به عوامل گسترده و روشهاى استفاده از نوشتافزار امرى ئافي ضرورى به نظر مىرسد. بالينحال، يافتههاى اين مطالعه

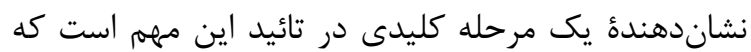
طرح مورد نظر مزاياى خاصى در استفاده از نوشتافزار نشان

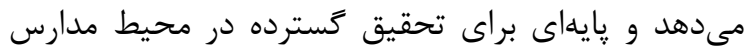

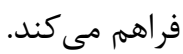
نتايج حاصل از تجزيهوتحليل دادههاى بهدستآمده نشان داد كه دانش آموزان در نواحى ساعد، شانه، بند اول

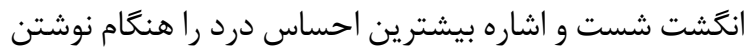

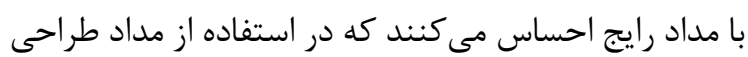

7. Salvendy G, Karwowski W. Advances in occupational, social, and organizational ergonomics. CRC Press; 2010. https://doi.org/ 10.1201/EBK 1439835074.

8. Zhang L, Helander MG, Drury CG. Identifying factors of comfort and discomfort in sitting. Hum Factors. 1996;38(3):377-89.

9. Cheng HY, Lien YJ, Yu YC, Ju YY, Pei YC, Cheng $\mathrm{CH}$, et al. The effect of lower body stabilization and different writing tools on writing biomechanics in children with cerebral palsy. Res Dev Disabil. 2013; 34(4):1152-9. https://doi.org/10.1016/j.ridd.2012. $\underline{12.019 .}$

10. Mououdi M. Comfort Evaluation of Penagain Ergonomic Pen with Traditional Pen (nonergonomic). sjimu. 2012; 20 (3) :46-54

11. Hasani S A, Mobaraki H, Moghadami Fard Z. The importance of ergonomics in increasing productivity and improving the performance of the staff of the Ministry of Health, Therapy and Medical Education. tkj. 2013; 4 (4) :92-101 